\title{
Information Extraction and Dynamic Monitoring of Autumn Grain Crops in Heishan Area Based on Landsat8 Remote Sensing Image
}

\author{
DingHua $^{1}$, Li Ruren ${ }^{1 *}$, and Liu Yumei ${ }^{1}$ \\ ${ }^{1}$ Shenyang Jianzhu University, No 9 Hunan East Road, Hunnan New District, Shenyang, China
}

\begin{abstract}
Based on not only the basic data of total 9-phase Landsat8 OLI remote sensing images from 2013 to 2016 in Heishan District, Jinzhou City, Liaoning Province, also the supplementary data of highresolution remote sensing images and elevation data in Heishan District, as well as phenology data in Northeast of China, the remote sensing images of the studied areas were classified by various methods and the classification results were evaluated accurately. The results show that the method of object-oriented classification obtains the best effect and highest precision on the information extraction of autumn grain crops. Its overall spatial distribution accuracy is about $95.2091 \%$, and the Kappa coefficient is 0.9360 . The method of object-oriented classification was applied to the dynamic monitoring of autumn crops in the researched areas in recent years, and then the analysis of the main autumn crops in there from 2013 to 2016 showed that the rice areas increased significantly in the past four years, while the corn areas have shrunk by nearly one-fifth.
\end{abstract}

\section{Introduction}

As the important data source of spatial geographic information in the 21 st century, the remote sensing technology has characteristics like wide observation range, diversified information collection technology, rapid data-obtaining speed, short period and realization of dynamic monitoring, which is widely applied in aspects of crop recognition, disaster monitoring, area measurement, output estimate and so on. However, the crop planting area in our country is large, the planting structure is complex, and the land parcel is relatively broken, generally with the phenomenon of "same object with different spectra and different objects with the same spectra". The traditional recognition method based on the spectra may cause the "phenomenon of spiced salt"; moreover, the complex spectra may cause the influence on the classification recognition, and reduce the classification accuracy.

With the rapid development of remote sensing technology, the object-oriented classification method is widely applied in the classification of medium-high resolution remote sensing image. The object-oriented method can comprehensively consider the spectral information of pixel, textural features and spatial structure and relation of the object on the earth's surface, reduce the traditional problem of spiced salt error that exists in the classification method based on the spectrum, enhance the classification accuracy, and effectively eliminate the "problem of spiced salt" of the traditional pixel classification. However, the plantation structure of autumn grain crops is complex, and the object-oriented method is difficult to guarantee to mark out the "pure" pattern spot of crops at the corresponding period, which may cause the interfusion of different crops in the same pattern spot and lead to the reduction of recognition accuracy.

Aiming at the above problem, basing on landsat 8 remote sensing image, the discussion and analysis on the recognition methods for autumn grain crops are made by combining the traditional classification method based on the pixel and object-oriented method with the high resolution historical image of the research area, and the information extraction and dynamic monitoring of autumn grain crops are performed by selecting the proper method

\section{Data preparation and general situation of research area}

Heishan county is selected as the research area in this paper. Heishan county is a county under the jurisdiction of Jinzhou city in Liaoning province, which is located in the west of Liaoning province. It is in the northeast of Jinzhou. It is also a county of national commodity grain base or advanced county of national grain production. The total output of grain throughout the year is over 1.2 billion jin. The research area is located in the east longitude of $121^{\circ} 49^{\prime}$ to $122^{\circ} 36^{\prime}$ and northern latitude of $41^{\circ} 29^{\prime}$ to $42^{\circ} 08^{\prime}$. It is adjacent to Liaozhong region of Shenyang city and Xinmin city along Raoyanghe River

\footnotetext{
* Corresponding author: cerurenLi@sjzu.edu.cn
} 
in the east, borders on Tai'an county of Anshan city in the south and Beizhen city in the west, and closes to Mongolia autonomous county of Fuxin in the north and northwest. Heishan county is located in the semi-humid region of temperate zone, which belongs to continental monsoon climate of temperate zone. The annual average temperature is $8^{\circ} \mathrm{C}$. The average temperature in January is $-10.7^{\circ} \mathrm{C}$, and the lowest temperature is $-27.6^{\circ} \mathrm{C}$; the average temperature in July is $24.2^{\circ} \mathrm{C}$, and the highest temperature is $35^{\circ} \mathrm{C}$. The annual average rainfall is $586 \mathrm{~mm}$, and the frost-free season is about 165 days. The natural conditions of Heishan county decide one crop per annum. The autumn grain crops center on corn and rice, and a small number of peanuts and so on.

The Landsat8 remote sensing image data of nine periods in total in 2013 to 2016 is used in the research: according to the growing period of autumn grain crops in the research area, the data of six periods in May to October of 2016 is selected; and the data of one period with relatively low cloud cover in July of 2013, 2014, and 2015 is respectively selected. Before performing the relevant research, it is necessary to perform the image preprocessing on the remote sensing data of nine periods like radiometric calibration, atmospheric correction, image fusion and image cropping and so on. Except for the remote sensing image, there is also DEM auxiliary data. In BIGEMAP, the altitude data of the highest resolution series (level L16) in the research area that is available for download is selected, and the resolution ratio of pixel can reach $1.78 \mathrm{~m}$.

\section{Research content and main research method}

\subsection{Research content}

The main content of the research is to extract the information of remote sensing image of Heishan county in Liaoning province by taken Landsat8 OLI remote sensing image as the basic remote sensing image data, and perform the feature analysis of ground object spectral, topographic feature extraction, and analysis on separability of ground object, so as to finally obtain the distribution diagram of autumn grain crops of Heishan county, and perform the analysis on the dynamic monitoring of distribution changes of autumn grain crops in Heishan county in recent years.

\subsection{Spectral analysis and research on separability}

The spectral feature of ground object reflection is widely applied in the remote sensing image classification. It is the most important, fundamental and direct element of interpretation classification. The remote sensing image of six periods in May to October of 2016 after preprocessing is loaded in ENVI to conduct 2\% linear stretch, which is modified with wave band display of 6,5 , $2(\mathrm{R}, \mathrm{G}, \mathrm{B})$. This kind of wave band combination mode increases the difference between ground objects to make the level of image clearer. Through the spectral analysis, the remote sensing image of three periods in May, September and October of 2016 is abandoned, the training samples of all kinds of land types on the remote sensing image of three periods in June, July and August are selected, and the samples of training region (ROI, Region of Interest) are built with 6 kinds of land use methods.

The separability of data between six kinds of land use types like rice, woodland, building, corn, waters and bare land of three periods in June, July and August of 2016 are calculated in the research. The results show that, rice and woodland are least likely to separate in six kinds of land use types, because the spectral features of reflection of these two kinds of land types are similar in these periods. Only in specific period, some difference of reflectance value at a wave band of remote sensing image may be caused. Therefore, when performing the classification on these two kinds of ground objects, it is necessary to choose more training regions and select the high resolution remote sensing image data as the reference. Except for the data of August that is seriously influenced by atmospheric image, we discover that the separability of the sample on July 2nd of 2016 is the best. The classification and research are made further by selecting the data in this period.

\subsection{Contrastive research of classification method}

The classification on six kinds of ground objects in the research area is made by adopting four kinds of classification methods in this paper: unsupervised classification based on ISODATA algorithm, three kinds of supervised classification methods like maximum likelihood method (Maximum Likelihood), minimum distance method (Minimum Distance), method of support vector machine (Support Vector Machine Classification) as well as object-oriented classification method based on the sample. We discover that the effect of object-oriented classification method is the best, and the accuracy is the highest through the contrast. The basic thought of object-oriented classification technology is to divide the remote sensing image in the research area into several regional spots with homogeny and homogeneity firstly, and then classify by utilizing some feature information in the divided regional spots, mainly including four parts like image division, feature extraction, classification rule and information extraction. The classification is made by adopting $\mathrm{K}$ adjacent method in the research. $\mathrm{K}$ adjacent method is to calculate the Euclidean distance of training region sample in $\mathrm{N}$ dimensional space after classifying the divided spots and making statistics, so as to obtain the classification result.

\subsection{Contrastive research of classification method}

The quantitive analysis on the changes of land in Heishan area in 2013-2016 is made respectively by utilizing the land transfer change matrixes. Taking the 
changes of land in 2013 to 2016 as the example, the land utilization transition diagram is obtained by utilizing the module of Thematic Change Workflow in the option of Change Detection in ENVI. The integral analysis on the changes of autumn grain crops in Heishan area in recent four years is made respectively by utilizing the transfer matrix and land utilization transition diagram.

\section{Result demonstration}

\subsection{Object-oriented classification result and accuracy assessment}

The object-oriented classification on the data of four periods in July 2013, 2014, 2015 and 2016 is disposed. The classification results are shown in Fig.1.

The statistics on the pixel value of all kinds of land use types over the years has been made by utilizing the Statistic (statistic) tool provided by ENVI software. According to the total number of pixel of statistic autumn grain crops, the planting area (planting area $=$ number of pixel $\times$ pixel area, pixel area in this paper $=$ $15 \times 15$ ) is calculated, so as to obtain the changes of planting area of autumn grain crops in 2013 to 2016, as shown in Table 1

As shown in Table 1, the planting area of rice in 2013 to 2016 increased year by year, the growth trend in 2013 to 2014 was slow, the planting area of rice in 2014 began to increase greatly, and that in 2016 increased $31.53 \%$ by comparing with that in 2013 ; accordingly, the planting area of corn decreased year by year, and that in 2016 decreased $20.61 \%$.

The classification results of Fig. 3 are disposed after the classification, and the accuracy assessment on the classification results is made by utilizing the actual region of interest to verify the samples. The actual region of interest is selected on the high resolution image of the same month of every year, and the confusion matrixes of accuracy assessment over the years are obtained finally. Its overall classification accuracy and kappa coefficient are shown in

\subsection{Analysis on land use changes}

Taking the changes of land in 2013 to 2016 as the example, the land utilization transition diagram is obtained by utilizing the module of Thematic Change Workflow of ENVI, taking 2013.07-class as the front time phase classification diagram and 2016-07-class as the rear time phase classification diagram, and setting up the proper value to eliminate the noise and merge small spots, as shown in Fig. 4. The land utilization transfer matrixes in 2013 to 2016 are obtained by utilizing the module of Change Detection Statistics, as shown in Fig. 2.

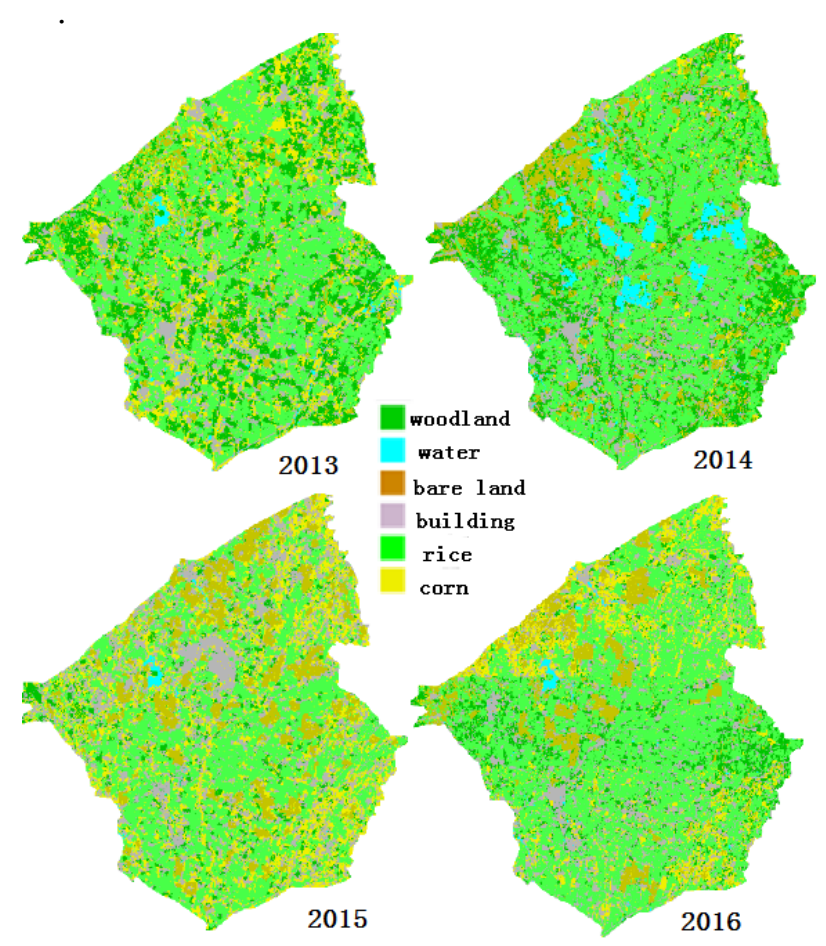

Fig. 1. Land classification results of research area in 2013 to 2016

Table 1. Statistical table of area of autumn grain crops in 20132016.

\begin{tabular}{|c|c|c|c|c|}
\hline $\begin{array}{l}\text { Crop } \\
\text { type } \\
\text { Area/ha. }\end{array}$ & $\mathbf{2 0 1 3}$ & $\mathbf{2 0 1 4}$ & $\mathbf{2 0 1 5}$ & $\mathbf{2 0 1 6}$ \\
\hline Rice & 94045.29 & 94810.43 & 104675.16 & 123701.58 \\
\hline Corn & 42865.78 & 41791.52 & 40328.06 & 34032.98 \\
\hline
\end{tabular}

Through the analysis of table.3, we can obtain that: the area of waters in 2013 to 2016 totally decreased $49.49 \%$, that of woodland totally decreased $58.79 \%$, that of building land totally increased $5.44 \%$, and that of bare land totally increased $129.1 \%$; the planting area of rice in autumn grain crops totally increased $31.53 \%$, and that of corn totally decreased $20.61 \% ; 14.94 \%$ of waters, $60.5 \%$ of woodland, $40.37 \%$ of corn field, $14.38 \%$ of building land, and $48.26 \%$ of bare land turned into paddy field in four years; $10.34 \%$ of paddy field replanted with corn, $7.3 \%$ of waters, $13.24 \%$ of woodland, $10.34 \%$ of paddy field, $12.33 \%$ of building land, $17.6 \%$ of bare land turned into corn field, and $40.37 \%$ of corn field replanted with rice. 
Table 2. Statistical table of area of autumn grain crops in 20132016

\begin{tabular}{|c|c|c|c|c|}
\hline $\begin{array}{c}\text { Assessment } \\
\text { index value }\end{array}$ & 2013 & 2014 & 2015 & 2016 \\
\hline $\begin{array}{c}\text { Overall } \\
\text { accuracy }\end{array}$ & $96.94 \%$ & $70.66 \%$ & $86.89 \%$ & $95.21 \%$ \\
\hline $\begin{array}{c}\text { Kappa } \\
\text { coefficient }\end{array}$ & 0.9566 & 0.6062 & 0.8175 & 0.9360 \\
\hline
\end{tabular}

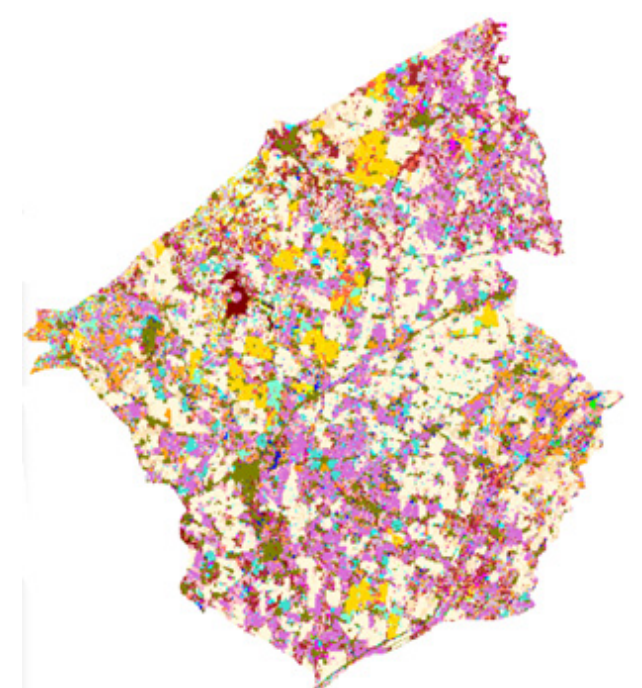

Fig.2. Land utilization transition diagram in 2013 to 2016

Table 3. Land utilization transfer matrixes in 2013 to 2016

\begin{tabular}{|c|c|c|l|l|l|l|}
\hline $\mathrm{Km}^{2}$ & water & $\begin{array}{c}\text { Forest } \\
\text { land }\end{array}$ & $\begin{array}{l}\text { Bare } \\
\text { land }\end{array}$ & paddy & maize & $\begin{array}{l}\text { Buildin } \\
\text { g/road }\end{array}$ \\
\hline water & 36.97 & 0.048 & 0.016 & 0.278 & 0.530 & 0.087 \\
\hline $\begin{array}{c}\text { Forest } \\
\text { land }\end{array}$ & 8.943 & 13.31 & 6.896 & 14.02 & 6.194 & 8.001 \\
\hline $\begin{array}{c}\text { Bare } \\
\text { land }\end{array}$ & 0.827 & 6.519 & 11.85 & 7.521 & 3.738 & 20.90 \\
\hline paddy & 14.95 & 60.50 & 64.45 & 40.37 & 14.37 & 48.26 \\
\hline maize & 7.303 & 13.24 & 10.35 & 22.72 & 12.33 & 17.16 \\
\hline $\begin{array}{c}\text { Buildin } \\
\text { g/road }\end{array}$ & 31.01 & 6.386 & 6.429 & 15.08 & 62.83 & 5.595 \\
\hline
\end{tabular}

\section{Conclusion}

The Landsat8 OLI remote sensing satellite image with nine time phases in total in 2013, 2014, 2015 and 2016 is selected in the research. Taken the topographic data, phenology data, high resolution image and other thematic data in the research area as the auxiliary, the information extraction and dynamic monitoring of autumn grain crops in Heishan county are performed by respectively adopting unsupervised classification method, supervised classification method and object-oriented classification method, so as to made the further research and comparison on the extraction method of autumn grain crops. The main conclusion shall be as follow:

(1) Through the spectral analysis on the main land use type and analysis on separability of remote sensing image with six time phases in the research area in 2016, we can obtain that, the best period for the information extraction of autumn grain crops in Liaoning area is July or August by taking Heishan county as the representative.

(2) The information extraction of autumn grain crops in the research area is performed by utilizing four kinds of classification methods in the research. The results show that, the effect of the object-oriented classification method is the best for the information extraction of autumn grain crops, the accuracy is the highest, which can be taken as the method of main basis for the extraction of autumn grain crops in Heishan county.

(3) The analysis on land use changes is made respectively on the image after the classification in 2013 to 2016. Through the analysis, we can discover that: the planting area of rice in 2013 to 2016 totally increased $31.53 \%, 14.94 \%$ of waters, $60.5 \%$ of woodland, $40.37 \%$ of corn field, $14.38 \%$ of building land, $48.26 \%$ of bare land turned into paddy field, and $10.34 \%$ of paddy field replanted with corn; the planting area of corn in four years totally decreased $20.61 \% .7 .3 \%$ of waters, $13.24 \%$ of woodland, $10.34 \%$ of paddy field, $12.33 \%$ of building land, $17.16 \%$ of bare land turned into corn field, and $40.37 \%$ corn field replanted with rice.

\section{References}

1. Qiong An, Bangjie Yang, Xianfeng Jiao, Journal of Agricultural Engineering, 23（8）,181(2014)

2. Yudong Cai, Wei Li, Weijie Xu, Remote Sensing of Land and Resources, 5 (4) : 63(2013)

3. Weibin Cao, Bangjie Yang, Jinpeng Song, Journal of Agricultural Engineering, 20 (4) ,112(2015)

4.Qingrui Chang, Ping'an Jiang, Yong Zhou, Guangrong Shen, Ruixue Li, Pengxiang Zhao, Introductory Theory of Remote Sensing Technology( Science Press, Beijing ,2012)

5. Liang Chen, Xi Liu, Yuan Zhang,Surveying and Mapping Engineering, 16 (3),40(,2013) 